\title{
Colon Tubulovillous Adenoma
}

National Cancer Institute

\section{Source}

National Cancer Institute. Colon Tubulovillous Adenoma. NCI Thesaurus. Code C5496.

A neoplasm that arises from the glandular epithelium of the colonic mucosa. It is

characterized by tubular and villous architectural patterns. The neoplastic glandular cells have dysplastic features. 